\title{
INTEGRASI SISTEM INFORMASI KEPUASAN BELAJAR MENGAJAR PROGRAM STUDI TEKNIK INFORMATIKA DENGAN SISTEM INFORMASI AKADEMIK UNRAM MENGGUNAKAN WEB SERVICE
}

\author{
(Integrating Teaching and Learning Satisfaction with Academic Information System \\ Using Web Service)
}

\author{
Fitri Bimantoro*, Ida Bagus Ketut Widiartha, I Gede Pasek Suta Wijaya, Ario Yudo Husodo \\ Program Studi Teknik Informatika, Fakultas Teknik, Universitas Mataram \\ Jl. Majapahit 62, Mataram, Lombok NTB, INDONESIA \\ Email: [bimo, widi, gpsutawijaya, ario]@unram.ac.id
}

\begin{abstract}
One of the tasks of a university is teaching. To keep the quality by improving the teaching qualifications, materials, teaching facilities, and infrastructure. but, one of the important things is to keep the quality of teaching. The quality of teaching can be measured from the feedback of the students. Informatics Department of Mataram University has a system to get feedback from its students called SIKBM (a questioner system for teaching). Unfortunately, not of all the students will fill this questioner because there is no interest for the students. So, we apply a web service system that connects SIKBM and SIA (academic information system). It will force the students to access SIKBM as a requirement to fill KRS (Course selection sheet) on SIA. The result shows that on even semester of 2017, we gain feedback for all of the courses we did not get in the previous years.
\end{abstract}

Keywords: web services, SIA, SIKBM, KRS, questionnaire

*Penulis korespondensi

\section{Pendahuluan}

Program Studi Teknik Informatika (PSTI) merupakan salah satu program studi yang paling diminati oleh mahasiswa yang dimiliki Universitas Mataram (Unram). PSTI yang bernaung di Fakultas Teknik ini mulai berdiri dari tahun 2012. Sampai saat ini PSTI sudah memiliki hampir 500 mahasiswa aktif, dan 13 dosen aktif yang kompeten di berbagai bidang tentang teknologi informasi. PSTI dalam menjaga mutu dan kualitasnya memiliki tim penjamin mutu yang melakukan analisis dan melakukan perencanaan untuk memperbaiki mutu pelayanan PSTI. Salah satu yang aspek yang diperhatikan oleh penjamin mutu adalah tentang kepuasan belajar mengajar.

Saat ini PSTI memiliki sistem informasi kuesioner untuk mendapatkan data kepuasan kegiatan belajar mengajar di PSTI. Adapun aspek yang tanyakan melalui kuesioner tersebut adalah tentang mata kuliah dan juga dosen. Selain mengumpulkan kuesioner, sistem ini akan langsung melakukan analisis kepuasan pelayanan dengan menggunakan metode Importance Performance Analisis (IPA). Hasil dari analisis metode IPA akan menunjukkan performa dari masing-masing dosen dari setiap mata kuliah yang diampu.

Dari segi fungsi, sistem informasi kuesioner ini dapat melakukan tugasnya dengan baik dan dapat menampilkan hasil yang sesuai dengan performa masing-masing mata kuliah dan dosen, namun sistem ini masih memiliki kekurangan. Kekurangan sistem ini terletak pada prosedur pengisian kuesioner yang dilakukan oleh mahasiswa. Walaupun kuesioner sudah terkomputerisasi, namun kuesioner belum dapat dipastikan terisi semua oleh mahasiswa, hal ini disebabkan belum ada prosedur efektif yang memaksa mahasiswa mengisi kuesioner, dan belum ada sanksi yang diberikan kepada mahasiswa jika tidak mengisi kuesioner.

Unram memiliki Sistem Informasi Akademik (SIA) yang berisi tentang seluruh informasi akademik termasuk nilai, dan juga pengisian KRS. Proses pengisian KRS di Unram dilakukan setiap awal semester melalui SIA, sedangkan nilai ditampilkan setiap akhir semester. Tiap melakukan pengisian KRS mahasiswa wajib mencetak KRS dan mengajukan pengesahan cetakan KRS ke PSTI. KRS yang dianggap sah ini akan dijadikan sebagai arsip baik oleh mahasiswa ataupun PSTI dan dapat digunakan dikemudian hari apabila terjadi kesalahan atau gangguan dari SIA.

Proses pengesahan KRS oleh PSTI mensyaratkan bukti pengisian kuesioner dari mahasiswa. Bukti pengisian kuesioner ini akan diberikan kepada staf 
PSTI, kemudian staf akan melakukan pengecekan pada sistem, dan akan memberikan pengesahan KRS jika mahasiswa benar-benar telah melakukan pengisian kuesioner. Namun prosedur ini ternyata cukup merepotkan staf, terutama ketika banyak mahasiswa yang melakukan pengesahan secara bersamaan, sehingga ada kemungkinan mahasiswa yang tidak melakukan pengisian kuesioner tetap mendapatkan pengesahan KRS.

Permasalahan yang dihadapi PSTI terkait pengisian kuesioner dan pengesahan KRS yang dihadapi PSTI tersebut disebabkan oleh belum terintregasinya sistem kuesioner dengan SIA. Untuk itu, perlu dilakukan integrasi SIA dengan sistem informasi kuesioner dengan menggunakan API sehingga dapat mengatasi permasalahan tersebut. Integrasi ini dilakukan dengan aturan bahwa mahasiswa tidak akan dapat melihat nilai setiap akhir semester dan melakukan pengisian KRS tiap awal semester, jika tidak melakukan pengisian kuesioner yang telah disediakan oleh sistem. Dengan demikian, PSTI akan mendapatkan data kuesioner kepuasan kegiatan belajar mengajar dari seluruh mahasiswa, juga dapat mengoptimalkan kinerja staf prodi dalam melayani mahasiswa dalam memberikan pengesahan KRS.

\section{Penelitian Terkait}

Perkembangan API sudah dimulai dari dulu dan terus berkembang hingga saat ini[1]-[3]. Penggunaan Web Api kini tidak hanya digunakan pada aplikasi web saja[4]-[7], tetapi juga sudah merambah ke aplikasi mobile[8]-[11].

Simple Object Access Protocol (SOAP) merupakan standar web service yang dikeluarkan oleh W3C yang memanfaatkan XML untuk melakukan pertukaran informasi. SOAP mendefinisikan rule melalui tag-tag XML[12], [13]. Berbeda dengan SOAP, REST bukan merupakan standar web service yang dikeluarkan oleh organisasi. REST pertama kali dikenalkan oleh Roy Fielding[14]. REST menggunakan arsitektur yang sama dengang arsitektur HTTP, sehingga REST dapat melakukan operasi standar yang dilakukan oleh HTTP seperti GET, POST, PUT, dan DELETE. Pada beberapa penelitian mengemukakan bahwa REST lebih mudah untuk diterapkan baik itu aplikasi mobile ataupun berbasis web, selain itu penggunaan resource yang dipakai oleh REST jauh lebih sedikit daripada yang dibutuhkan oleh SOAP. Namun, SOAP lebih aman jika dibandingkan dengan REST[15]-[24].

Penggunaan web service pada Sistem informasi geografis yang digunakan untuk menampilkan informasi spasial tentang sumber daya alam memanfaatkan mapserver sebagai web gis server dan postgreeSQL sebagai basisdata dan juga bahasa pemrograman PHP untuk pengembangannya. selanjutnya menambahkan tag configurable Web Mapping Client Components (CWC2) pada halaman HTML agar dapat mendeploy konten peta pada aplikasi web[25].

Penggunaan REST web service dengan format JSON dievaluasi dengan menerapkannya pada aplikasi mobile. Penerapan Web service pada sales tracking dan sales order menggunakan format JSON memberikan performa dan respon yang lebih cepat dibandingkan web services berformat XML, karena format JSON memiliki ukuran yang kecil dibandingkan dengna XML[9]. penerapan REST Web service juga digunakan untuk pencarian objek wisata pada aplikasi mobile. dengan memanfaatkan HTTPRequest, proses request aplikasi kemudian ditampilkan dalam format JSON[11].

penelitian yang lain, menggunakan web service untuk mengintegrasikan data melalui aplikasi mobile dan aplikasi web. implementasi aplikasi ini digunakan untuk memetakan relawan tanggap bencana yang langsung terhubung dengan Badan penganggulangan bencana daerah. Selain mampu memetakan relawan, aplikasi yang dibuat, mampu melakukan monitor, pencarian dan juga memungkinkan komunikasi yang dilakukan antar relawan[26].

SIKBM PSTI Unram merupakan sarana yang dibuat untuk mendapatkan respon mahasiswa terhadapa kegiatan belajar mengajar yang diberikan oleh PSTI. SIKBM berbasis web memungkinkan mahasiswa melakukan evaluasi mata kuliah dan dosen secara anonymous. Hasil dari SIKBM selanjutnya dapat dilihat oleh dosen yang bersangkutan dan juga evaluator. Nilai yang dihasilkan oleh SIKBM merupakan luaran dari proses hasil kuesioner menggunakan metode Importance Performance Analisys. Kekurangan dari SIKBM yang ada saat ini adalah, karena SIKBM belum terintegrasi dengan SIA Unram. Dampaknya, pengisian data KRS mahasiswa tidak terintegrasi secara otomatis[27][28].

Penggunaan teknologi web service dilakukan untuk mengintegrasikan data pada sumber data yang berbeda. Universitas Pendidikan Ganesha mampu menerapkan teknologi web service untuk menggabungkan data penelitian, kinerja dosen dan data pengabdian kepada masyarakat dengan luaran pada format yang berbeda yaknik JSON, XML, dan PHP Object[5].

pemanfaatan Access Token pada web service data masyarakat mampu meningkatkan keamanan masing- 
masing pengguna. penggunaan Access token memberi hak kepada administrator data penduduk untuk memonitor penggunaan data dan mengatur hak akses masing-msing access token[6].

Untuk itu pada penelitian ini, akan dilakukan integrasi SIKBM dengan SIA Unram menggunakan WEB API. Setelah dilakukannya integrasi ini, secara otomatis SIKBM akan membuka kuesioner terkait mata kuliah yang diambil oleh mahasiswa, serta permasalahan pengumpulan data akan menjadi lebih konsisten, karena mahasiswa tidak akan melakukan pengisian KRS sebelum menyelesaikan pengisian kuesioner pada semester sebelumnya.

\section{Metologi Penelitian}

\subsection{Alur Penelitian}

Alur penelitian ini mengikuti metode pendekatan waterfall. Pada metode ini pengembangan sistem dimulai dari tahap analisis, dimana pada tahap ini terjadi proses pencarian permasalahan yang ada, dan mengumpulkan data. Tahap selanjutnya adalah perancangan sistem, pada tahap perancangan sistem pendekatan yang digunakan dengan menggunakan UML. Hasil dari tahap ini akan menghasilkan penggambaran alur kerja sistem, cara pengoperasian sistem, hasil keluaran. Selanjutnya, tahap implementasi sistem berdasarkan tahap sebelumnya. Tahap implementasi dilakukan dengan melakukan pengodean dengan pendekatan Model View Controller (MVC). Setelah selesai tahap implementasi selanjutnya dilakukan pengujian, tahap ini bertujuan untuk melihat keunggulan dan kelemahan sistem. Adapun pendekatan metode waterfall diilustrasikan seperti pada Gambar 1.



Gambar 1. Alur Pengembangan Sistem

\subsection{Use Case Diagram}

Use case diagram adalah diagram yang digunakan untuk menerjemahkan kebutuhan sistem (system requirement) dan desain sistem. Gambar 2 menunjukkan use case diagram yang diusulkan. Pengguna (aktor) hanya mahasiswa PSTI. Mahasiswa yang akan melakukan pengisian KRS wajib untuk melakukan pengisian Kuesioner, begitu juga jika mahasiswa ingin melihat nilai mata kuliah setiap akhir semester.

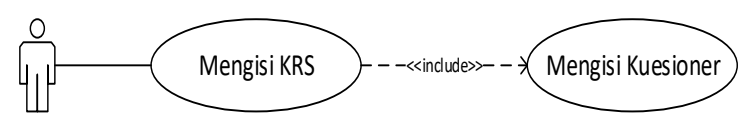

Gambar 2. Use Case integrasi SIKBM dan SIA Unram

\subsection{Sistem yang sudah ada}

Kondisi system yang sudah ada saat ini ditunjukan pada Gambar 3. terlihat pada Gambar 3 proses pengecekan pengisian kuesioner masih dilakukan secara manual oleh staf, sehingga dapat memicu kesalahan yang bersifat human error.

Sistem yang tersedia yang dimiliki oleh PSTI antara lain SIA yang menyediakan seluruh data terkait akademik mahasiswa, misalnya NIM, Nama, Mata Kuliah yang diambil pada tiap semester. Sehingga sangat memungkinkan untuk mengintegrasikan SIKBM yang membutuhkan data-data berupa NIM, dan Mata Kuliah yang diambil pada tiap semester untuk dievaluasi melalui sistem kuesioner.

\subsection{Sistem yang diajukan}

Tiga komponen utama dari sebuah web service digambarkan dalam Gambar 4. Berdasarkan Gambar 4, tiga komponen tersebut antara lain :

- Service provider, sebagai penyedia layanan webservice yang akan diakses oleh pengguna

- Service requestor, bertindak untuk melakukan permintaan layanan ke service provider

- Service registry, yang bersifat opsional agar service provider dapat mempublikasikan layanan-layanannya. 


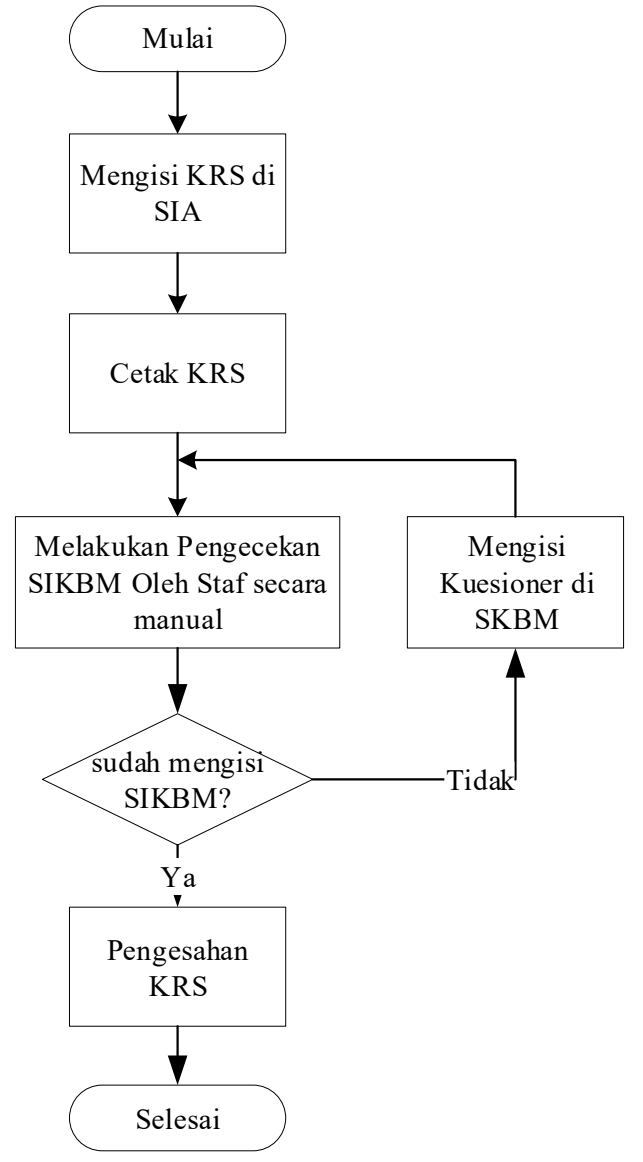

Gambar 3. Diagram Alir Proses pengisian KRS yang ada

Arsitektur Sistem yang diajukan dijelaskan seperti pada Gambar 5. Pada Gambar 5, Basisdata SIA dan SIKBM akan bertindak sebagai service provider yang akan menyediakan layanan penyedia data yang digunakan oleh service requestor. Service requestor dalam hal ini adalah Sistem informasi yang akan menggunakan data, dengan kata lain SIA dan SIKBM akan bertindak sebagai service requestor, dimana service requestor ini berupa aplikasi yang ditanamkan kedalam SIA dan SIKBM berupa modul integrasi.

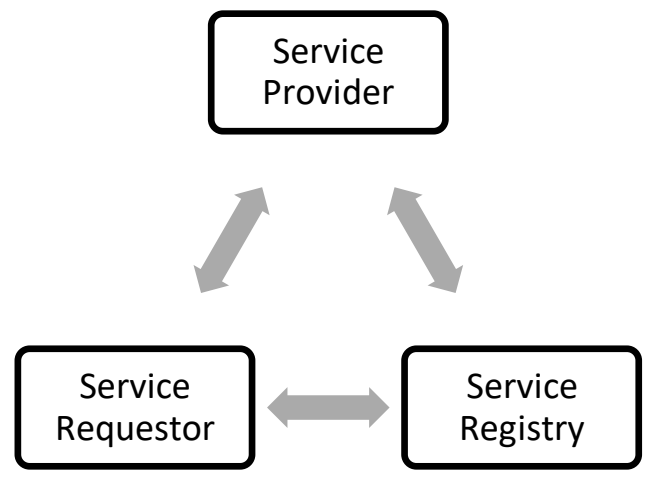

Gambar 4 Arsitektur Web Service [9]

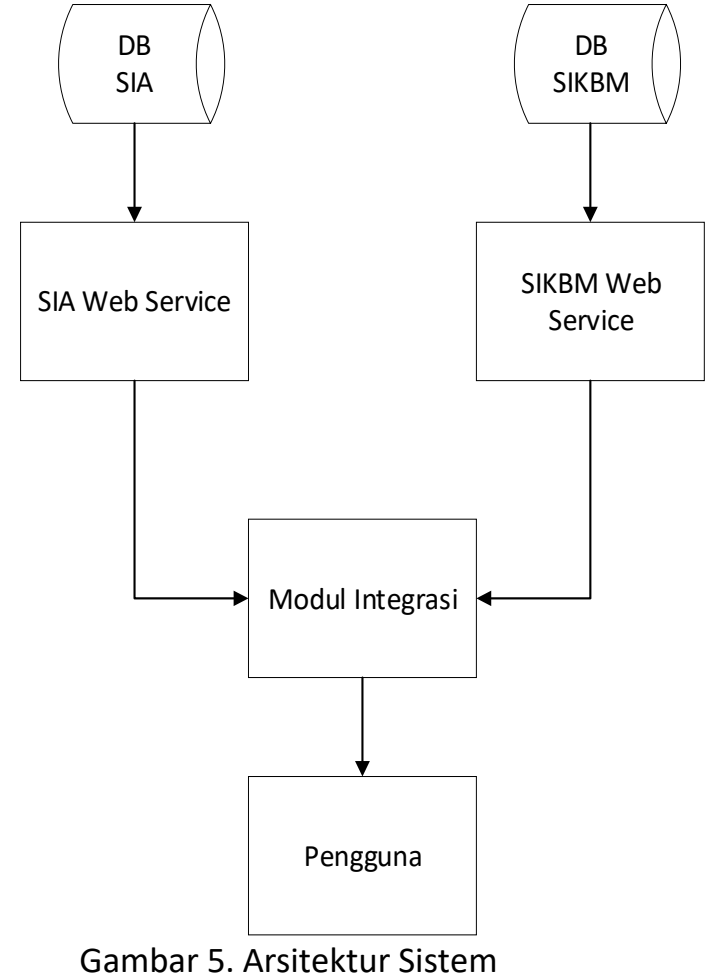

Layanan yang diberikan oleh SIA berupa data NIM, dan Mata Kuliah yang diambil pada semester aktif, sedangkan untuk SIKBM menyediakan data status pengisian kuesioner oleh mahasiswa. Data NIM, dan Mata Kuliah akan digunakan SIKBM untuk mendata Mata kuliah yang akan dievaluasi oleh mahasiswa, apabila proses evaluasi seluruh mata kuliah telah dilakukan, status pengisian kuesioner akan berubah menjadi True. Layanan status dari SIKBM kemudian akan diminta oleh SIA untuk mengaktifkan atau menonaktifkan layanan pengisian KRS oleh mahasiswa pada tiap semesternya.

Pada Gambar 6, dijelaskan proses yang diajukan untuk mengatasi kesalahan yang bersifat human error. Peran pengecekan yang sebelumnya dilakukan oleh staf, ditanamkan pada SIA sehingga, proses pengecekan dilakukan secara otomatis. Sehingga campur tangan manusia dalam mengambil keputusan dihilangkan. 


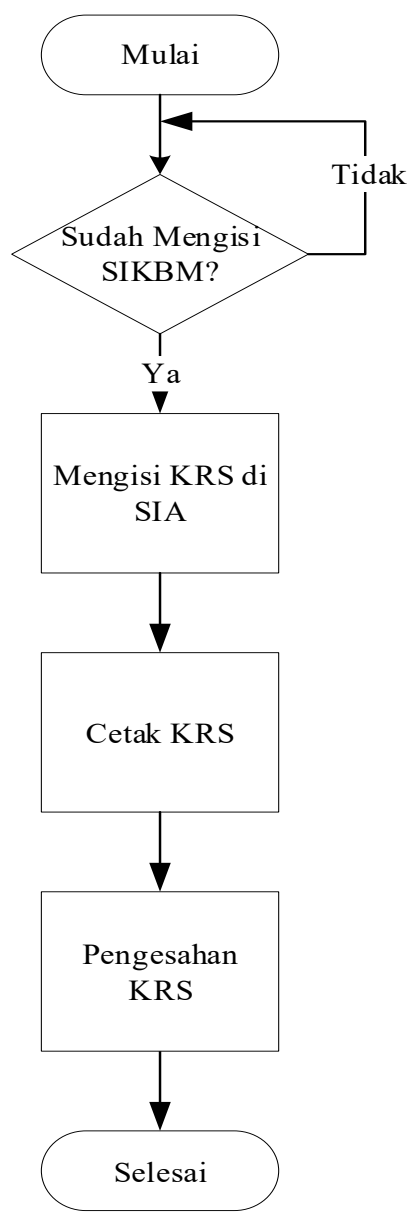

Gambar 6. Diagram Alir Proses pengisian KRS yang diajukan

\section{HASIL DAN PEMBahasAN}

Pada SIKBM proses pembuatan service provider menggunakan bahasa pemrograman PHP dan framework Laravel. Hasil queri data yang diinginkan oleh SIA yakni data status akan diencode dalam format data JSON seperti yang terlihat pada Gambar 7 dalam bentuk PHP Object.

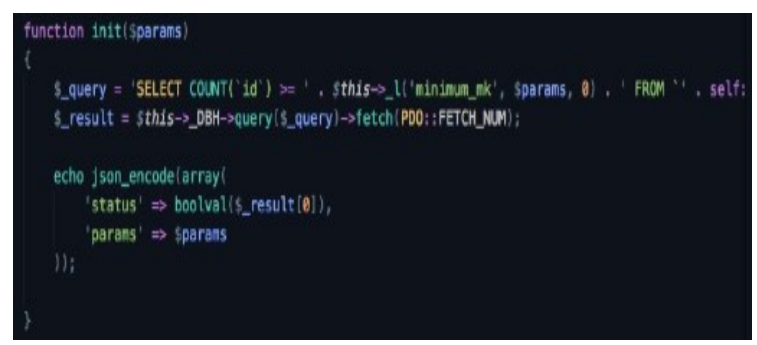

Gambar 7 Potongan Kode Service Provider SIKBM

Respon dari service requestor yang diminta oleh SIA ditampilkan pada Gambar 8 dalam format JSON dengan cara melakukan perintah request webservice

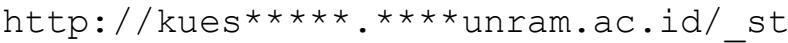
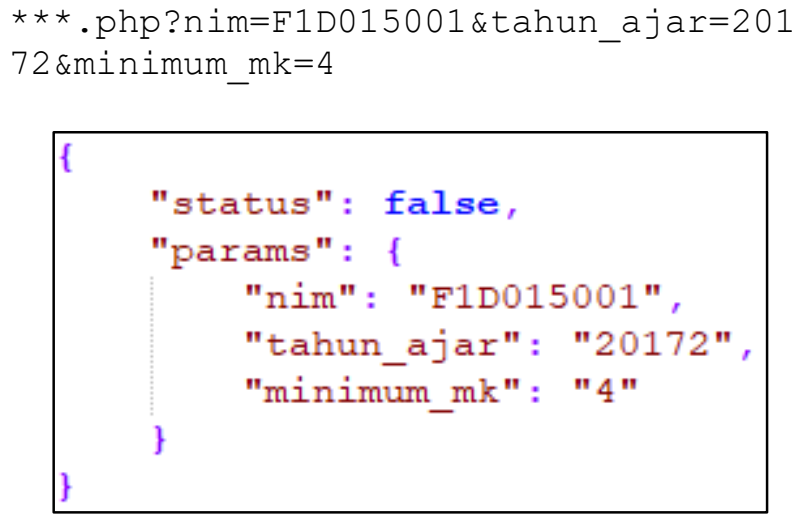

Gambar 8 Contoh Respon Layanan Web Service

Setelah dilakukan proses pengembangan sistem sesuai dengan perancangan pada bab metode penelitian, sistem diujikan pada proses pengisian KRS untuk periode Tahun Akademik 2018 Ganjil.Pada pengisian KRS periode 2018 Ganjil, Mahasiswa akan diarahkan untuk melakukan pengisian kuesioner pada SIKBM seperti yang ditunjukan pada Gambar 9. Pada Gambar 5 terlihat jelas bahwa tombol pengajuan KRS yang direncanakan tidak diaktifkan pada sisi mahasiswa, sehingga mahasiswa harus mengikuti arahan untuk melakukan pengisian KRS pada SIKBM seperti yang ditunjukkan tautan pada halaman pengisian KRS.

Untuk mengaktifkan fitur pengarahan pengisian SIKBM secara otomatis, pada sisi operator harus melakukan aktivasi fitur dengan mencentang Check Box cek status Kuesioner pada SIA. Selain itu, perlu ditambahkan mata kuliah yang tidak memerlukan pengisian kuesioner, antara lain Mata Kuliah Dasar Umum (MKDU), Praktik Kerja Lapangan, Kuliah Kerja Mandiri/Nyata, dan juga Tugas Akhir, atau mata kuliah lainnya yang dosen pengampunya bukan merupakan dosen tetap teknik Informatika Unram. Adapun tampilan laman operator terlihat pada Gambar 10.

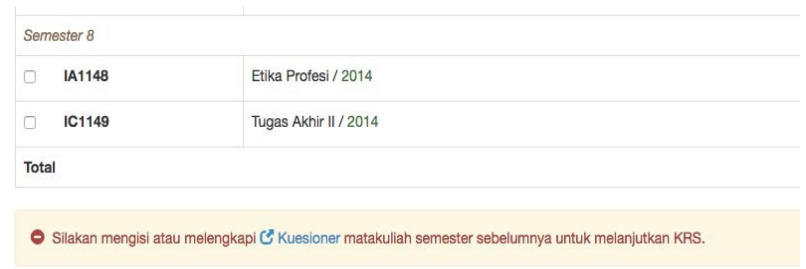

Gambar 9. Tampilan Pengajuan KRS saat Belum Mengisi SIKBM 


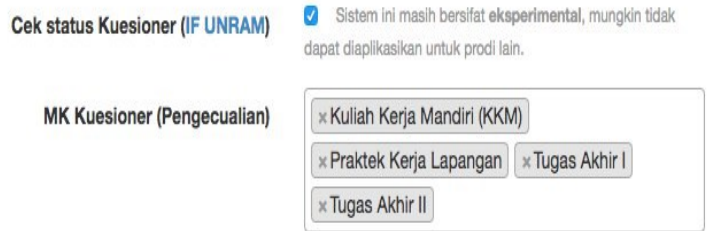

Gambar 10. Tampilan Aktivasi Fitur Pengisian SIKBM pada Operator SIA

Pada saat mahasiswa telah selesai melakukan proses pengisian SIKBM, tombol pengajuan KRS akan kembali diaktifkan pada laman pengajuan KRS di SIA. Pada Gambar 11, terlihat bahwa tautan pengisian kuesioner SIKBM telah dihilangkan dan diganti menjadi tombol ajukan untuk pengajuan KRS, sehingga mahasiswa dapat melakukan proses pengajuan KRS.

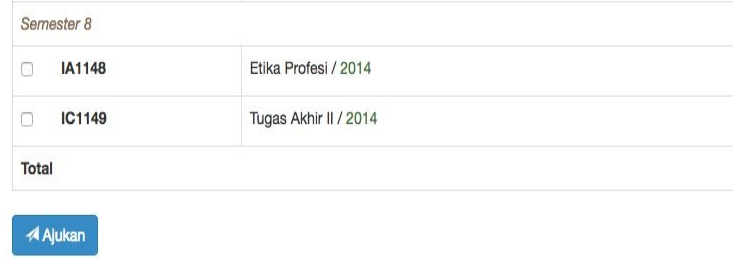

Gambar 11. Tampilan Pengajuan KRS Setelah Mengisi SIKBM

Pada sisi SIKBM, Gambar 12 menunjukkan hasil analisis SIKBM untuk periode Tahun Akademik 2017 Ganjil, dimana SIKBM telah dibuat namun proses SIKBM belum terintegrasi dengan SIA, sehingga tidak terdapat kontrol yang baik agar mahasiswa dapat mengisi kuesioner di SIKBM. Dampaknya, SIKBM tidak mampu memberikan evaluasi dari performa pengajaran dosen pada semester tersebut, karena data tidak terisi sepenuhnya.

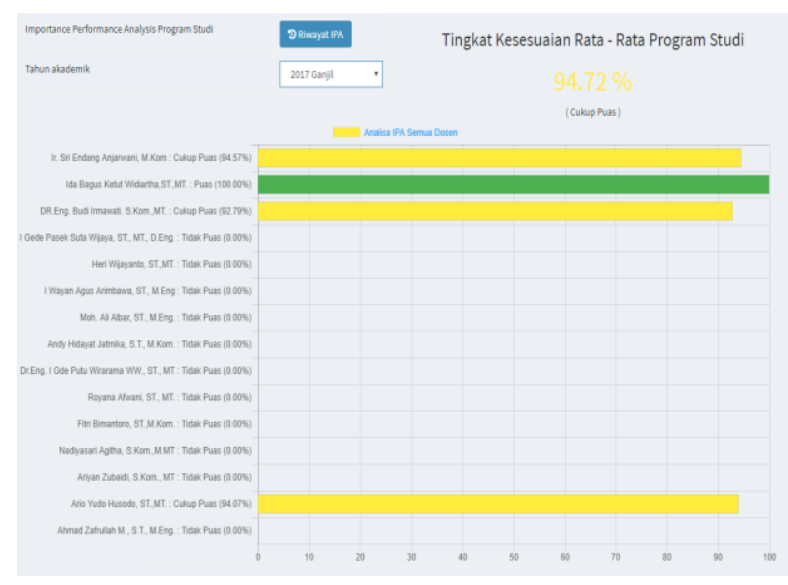

Gambar 12. Evaluasi Performa Dosen Mata Kuliah pada Periode TA 2017 Ganjil
Gambar 13 Menunjukkan bahwa integrasi SIA dengan SIKBM telah berhasil membuat mahasiswa untuk mengisi kuesioner performa dosen mata kuliah. Dapat dilihat bahwa pada Periode 2017 Genap, masing-masing mata kuliah yang diampu oleh dosen memberikan hasil evaluasi berdasarkan kuesioner yang diberikan oleh mahasiswa peserta mata kuliah dosen.

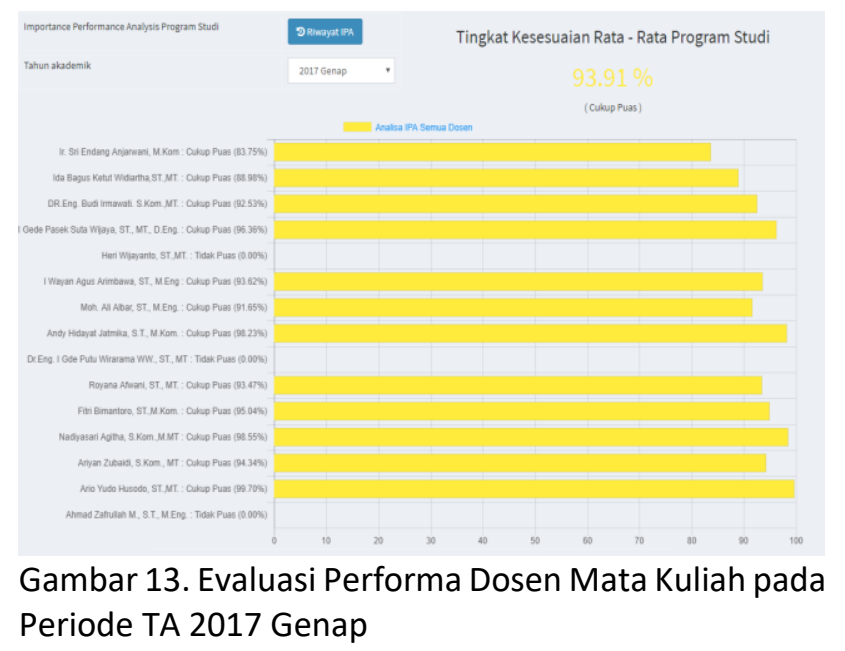

\section{KESIMPULAN DAN SARAN}

Berdasarkan pembahasan yang telah diuraikan pada bab sebelumnya, maka dapat ditarik kesimpulan sebagai berikut :

1. Pengembangan sistem dengan metode waterfall baik digunakan untuk penyusunan sistem ini, karena memberikan kesempatan yang seluasluasnya untuk merancang sistem secara detail sebelum diimplementasikan menjadi aplikasi.

2. Integrasi sistem SIA dan SIKBM dapat menjamin kebutuhan data umpan balik mahasiswa sebagai evaluasi dari dosen, sehingga dapat digunakan oleh dosen untuk memperbaiki performa pengajarannya yang mendukung tri dharma perguruan tinggi.

3. Dengan proses integrasi dapat menghilangkan human error dari pengguna sehingga data yang masuk lebih reliable.

Saran untuk pengembangan selanjutnya, perlu dilakukan evaluasi terhadap metode analisis performa yang paling sesuai untuk diterapkan pada performa mengajar dosen di Teknik Informatika Unram, untuk meningkatkan mutu dan kualitas pengajaran di Teknik Informatika Unram, dan seluruh Program Studi Di Unram pada umumnya. 


\section{DAFTAR PUSTAKA}

[1] P. Fremantle and R. Boakes, "A History and Future of Web APIs Information Technology A History and Future of Web APIs," no. April 2015, 2014.

[2] M. Maleshkova, C. Pedrinaci, and J. Domingue, "Investigating Web APIs on the World Wide Web," in The 8th IEEE European Conference on Web Services (ECOWS 2010), 2010.

[3] E. Wittern et al., "Opportunities in Software Engineering Research for Web API Consumption," in 2017 IEEE/ACM 1st International Workshop on API Usage and Evolution (WAPI), 2017, pp. 7-10.

[4] M. Yazdi, "Implementasi Web-Service pada Sistem Pelayanan Perijinan Terpadu Satu Atap di Pemerintah Kota Palu," in Seminar Nasional Teknologi Informasi \& Komunikasi Terapan 2012 (Semantik 2012), 2012, pp. 450-457.

[5] A. A. G. Y. Paramartha, N. K. Kertiasih, and G. R. Dantes, "Integrasi Data Penelitian, Pengabdian Kepada Masyarakat, dan Kinerja Dosen di Universitas Pendidikan Ganesha," pp. 314-320, 2016.

[6] M. I. Perkasa and E. B. Setiawan, "Pembangunan Web Service Data Masyarakat Menggunakan REST API dengan Access Token," Ultim. Comput., vol. X, no. 1, pp. 19-26, 2018.

[7] Taufiqurrohman and A. Iwan Nurhidayat, "Rancang Bangun Sistem Integrasi Antara Desktop dan Web Aplikasi Di Toko Parfum Confi," J. Manaj. Inform., vol. 5, no. 2, pp. 37-41, 2016.

[8] A. Rulloh, D. E. Mahmudah, and H. Kabetta, "Implementasi REST API pada Aplikasi Panduan Kepaskibraan Berbasis Android," Teknikom, vol. 1, no. 2, 2017.

[9] E. Kurniawan, "Implementasi Rest Web Service Untuk Sales Order dan Sales Tracking Berbasis Mobile," EKSIS, vol. 7, no. 1, pp. 1-12, 2014.

[10] J. Thoha, C. Anam, A. Susanto, and U. D. Nuswantoro, "Sistem Rekap Data Migrasi Infrastruktur dengan Rest Web Service Berbasis Android ( Studi Kasus pada PT. Telkom Askes )," Univ. Dian Nuswantoro, pp. 1-9, 2016.

[11] D. Ulhaq and Z. Alamsyah, "Implementasi Web Service Dalam Pencarian Objek Wisata Berbasis Android," in Seminar Nasional Teknologi Informasi dan Multimedia, 2017.

[12] F. Belqasmi, R. Glitho, and C. Fu, "RESTful Web Services for Service Provisioning in Next-Generation Networks: a Survey," IEEE Commun. Mag., vol. 49, no. 12 , pp. 66-73, Dec. 2011.

[13] M. Zekriyapanah Gashti, "Investigating Soap And Xml Technologies in Web Service," Int. J. Soft Comput., vol. 3, no. 4, 2012.

[14] Fielding and R. Thomas, "Architectural Styles and The Design Of Network-Based Software Architectures," University of California, Irvine, 2000.

[15] R. Van Den Broek, "Comparing the Performance of
SOAP and REST PHP Clients," in 14th Twente Student Conference on IT, 2011.

[16] M. Tsenov, "Web Services Example with PHP/SOAP," in International Conference on Computer Systems and Technologies-CompSysTech, 2006.

[17] F. Belqasmi, J. Singh, S. Y. Bani Melhem, and R. H. Glitho, "SOAP-Based vs. RESTful Web Services: A Case Study for Multimedia Conferencing," IEEE Internet Comput., vol. 16, no. 4, pp. 54-63, Jul. 2012.

[18] M. K. Nair and V. Gopalakrishna, "Applying Web Services with Mobile Agents for Computer Network Management," Int. J. Comput. Networks Commun., vol. 3, no. 2, 2011.

[19] B. Upadhyaya, Y. Zou, H. Xiao, J. Ng, and A. Lau, "Migration of SOAP-based Services to RESTful Services," in 2011 13th IEEE International Symposium on Web Systems Evolution (WSE), 2011, pp. 105-114.

[20] H. Zhao and P. Doshi, "Towards Automated RESTful Web Service Composition," in 2009 IEEE International Conference on Web Services, 2009, pp. 189-196.

[21] K. Wagh and R. Thool, "A Comparative Study of SOAP Vs REST Web Services Provisioning Techniques for Mobile Host," vol. 2, no. 5. International Institute for Science, Technology and Education (IISTE), 2011.

[22] C. Pautasso, O. Zimmermann, and F. Leymann, "RESTful Web Services vs. 'Big' Web Services: Making the Right Architectural Decision," in $W W W$ '08 Proceedings of the 17th international conference on World Wide Web, 2008.

[23] A. Dudhe and S. Sherekar, "Performance Analysis of SOAP and RESTful Mobile Web Services in Cloud Environment," Int. J. Comput. Appl., pp. 1-4, 2014.

[24] J. Tihomirovs and J. Grabis, "Comparison of SOAP and REST Based Web Services Using Software Evaluation Metrics," Inf. Technol. Manag. Sci., vol. 19, no. 1, pp. 92-97, 2017.

[25] P. S. Singh, D. Chutia, and S. Sudhakar, "Development of a Web Based GIS Application for Spatial Natural Resources Information System Using Effective Open Source Software and Standards," J. Geogr. Inf. Syst., vol. 04, no. 03, pp. 261-266, Jun. 2012.

[26] T. D. Indriasari, K. Anindito, E. Julianto, and B. L. P. Pangaribuan, "A Mobile and Web Application for Mapping Disaster Volunteers' Position in Indonesia," Int. J. Interact. Mob. Technol., vol. 11, no. 3 , p. $98,2017$.

[27] D. G. Febrian, "Sistem Informasi Belajar Mengajar di Program Studi Teknik Informatika Universitas Mataram Menggunakan Informatika Universitas Mataram Menggunakan Importance Performance Analysis," Mataram, 2017.

[28] Syaifullah, I. G. P. S. Wijaya, and A. Y. Husodo, "Sistem Informasi Kepuasan Layanan Administrasi 
Akademik Berbasis IPA (Importance Performance Analysis ) Studi Kasus Fakultas Teknik Universitas Mataram Study Case on Faculty of Engineering , Mataram University)," J-Cosine, vol. 2, no. 1, pp. 37-43, 2018. 